\title{
A Case Study of Foreigner's Intercultural Identity in China via WeChat Moments
}

\author{
Ju Bei, ${ }^{1, *}$ \\ ${ }^{1}$ International Business Faculty, Beijing Normal University Zhuhai Campus, China University of \\ Macau, PhD student
}

\begin{abstract}
The study of communication and culture are interrelated with each other and with semiotics. This study attempts to explore the intercultural identity of foreigners via their use of social media in China. As the most popular social media used in China, a foreign teacher from America (named as Liz)'s posts via WeChat Moments from 2013 to 2015 were coded based upon photos and texts to indicate her identity in China. As a result of semiotic analyses, five main themes were identified in her posts, ranging from personal interests and needs, occupation, family, Chinese traits to American traits. Based upon these identified themes, Liz's intercultural identity as Chinese culture experiencer and promoter is reflected by her description of Chinese traditions, showing contrasts between American and Chinese culture, and using Chinese characters in writing. Overall, not much anxiety and stress during Liz's acculturation process are shown while most cultural posts reflect her active and ongoing adaption to Chinese culture.
\end{abstract}

\section{INTRODUCTION}

When new comers come in contact with people of different cultural backgrounds, identity variation takes place. Thus intercultural identity has often played a crucial role in intercultural communication. As [1] has pointed out "through face-to-face or mediated forms of communication, intercultural interfaces often present a multiple of challenges, including those that force people to confront and re-assess their own identity as well as the taken-for-granted practices of thinking, feeling and acting associated with identity (p.10)". As one of the most popular mediated forms of communication in China, WeChat Moments provides users with the platform to post what they believe and what they prefer. Meanwhile, the attitudes and well-being of WeChat Moments users are evaluated by their WeChat friends. Therefore, the present study targets at WeChat Moments of foreigners in China and tries to figure out what identities are hidden in their Moments posts. The better understanding of foreigners' identity in the host environment not only shows the ongoing cognitive and behavioral variations of foreigners but contributes to their successful acculturation.

\footnotetext{
*Corresponding author: jubei@bnuz.edu.cn
} 


\section{Literature Review}

\subsection{Identity in Intercultural Communications}

In combination of personal and social factors in individual's identity, cultural identity has occupied the investigations of one's identity in intercultural communication. A new comer' cultural identity is initially perceived to be negotiable and manageable. Characterized as enduring and changing, [2] implied that cultural identities occur in daily discourse and social practices, and then are transmitted to other communicators. In [3,4] identity negotiation theory, an individual's developmental skills for competent identity negotiation are the center of effectively applying his/her knowledge of cultural and ethnic identity salience in diverse interactions. Drawn both from cultural identity theory and identity negotiation theory, [5] identity management theory stated that individuals are able to manage their cultural identities and facework when communicating with people of different cultural backgrounds. Moving beyond the flexibility of cultural identity, [7] employed the term "intercultural identity" to highlight the evolving and adapting nature of identity.

As stated by Kim [6,7] development of intercultural identity is characterized by two interlocked elements: individuation and universalization. As an individual rather a member of social category, one is able to clearly define oneself and others based upon unique personal traits. Along with individuation in the identity transformation process, individuals are able to identity common humanity and complementarity among differences and conflicts. Not limited to one's own group membership, individuals are better to view themselves as a part of a larger whole. With the continuing acculturation and enculturation, new comers experience their psychological conditions of stress, adaptation and growth in the changing environment. The existing studies [8-10] have provided the convincing evidence to this conceptualization of identity transformation in intercultural contacts.

\subsection{Identity Studies in China}

The highlight of identity studies [11-13] in China have focused on the empirical investigation of factors influencing social identity of migrant workers from rural to urban places and that of their children. Studies [14,15] targeting at foreigners including international students in China have mainly explored their acculturation situations. In [15]'s study, the good performances of foreigners in the level of economic situation and social interaction have been found. However, insufficient cultural and psychological integration of foreigners lead to their weak social interpenetration in overall. Certainly, Chinese scholars have attempted to discuss their own understanding of cultural identities. [16]'s explanation narrated the maturity development of intercultural identity involves three stages from unconscious, conscious to creative stage. Theoretically, starting from ethnocentrism, conscious intercultural identity characterized by reflective thinking and extended referencing is a threshold for new comes to go beyond before they finally accomplish selftransformation from ethnocentric to intercultural. Nevertheless, no studies exploring the foreigners' identity in China have yet been conducted. For this reason, the present study aims to investigate how foreigners perceive and develop their identity in intercultural contact with Chinese people. The better identity recognition will facilitate foreigners' acculturation into the new culture and establish their sense of belongs.

\section{Research Questions}


Launched by Tencent Company in 2011, WeChat has gained the greatest popularity on account of its interactive and personalized services. In its menu, four columns as Chats, Contacts, Discover and Me are displayed in navigation bar [17]. "Moments" (Peng you quan) means sharing the moments (posts about pictures, photos, texts and videos) with friends could be selected in the Discover. On the assumption that the usage of ethnic media contributes to the newcomers' acculturation in dominant culture, WeChat, as mediated form of communication, is of priority for foreigners to interact with Chinese people. Agreed upon [18]'s elaboration, symbols can serve as markers of identity ranging from national, occupational, religious to gender. Therefore, WeChat Moments is believed to be one form of symbols which include objects, behaviors, texts, ideas and people. In the present study, the semiotic analysis of foreign user's WeChat Moments is under discussion to answer the first question:

- What themes could be identified in WeChat Moments used by foreigners?

Based upon the description of thematic meanings shared in WeChat Moments, this study attempts to reveal the identities of foreign users via their use of host country media. Therefore, the following question is asked:

- How foreigners' intercultural identity is represented via WeChat Moments?

\section{Methods}

Defined by [18], culture is "a set of systems or codes of symbols and meanings, of communication as human symbolic activity". The study of communication and culture are interrelated with each other and with semiotics. Therefore, the semiotic analyses (based upon photos and texts) of foreigners' posts of WeChat Moments are conducted to uncover their intercultural identity when they are coming to China as newcomers. Liz (pseudonym) is from America and now is working as an IELTS Teacher for $2+2$ program in one of universities in Zhuhai, Guangdong Province, China. Through her frequent updating posters in Moments, Liz shared lots of information about her work and life in Zhuhai with her WeChat friends including me. She was chosen to be the representative of foreigners in Zhuhai. And a case study (analysis of Liz's WeChat Moments) was conducted to discover her identities represented via WeChat.

Meanwhile, I have obtained Liz's consent for this study. Over January 15, 2013 to December 31, 2015, Liz has totally posted 138 posts and 1 short-video post via her WeChat Moments. Most posts have the photos with the texts in the bottom or the pictures with words, except for only three photo posts without text. Deleting three posts with no reference of words, 135 posts consequently were under analysis to identify themes which manifest a foreigner's identity in host environment. Moreover, if several photos are grouped in one post, only one screen shot is taken out in the present study due to the same topic shared. Then all 135 posts are coded based upon the photos and text illustrated in WeChat Moments. With regards to the photos whose meanings are vague, the texts act as complement to decide what topics are talking about. The post is not exclusive to each other. Some posts express multiple themes so they are repeatedly counted in each category. Take a post as an example, the screen shot primarily conveys the theme about Chinese culture by showing the red Chinese characters (xin nian kuai le meaning happy New Year) and the Chinese zodiac which indicates 2014 is the year of horse. In the bottom, the text acts as a reminder of class cancellation and exam. Therefore, this screen shot is counted as the post expressing both themes of Chinese culture and occupation.

More specifically, the posts describing her hobbies such as travelling (via food, scenery), hiking, gardening are labeled as personal interest. The posts with raised question like "Anyone know a good, trusted camera repair shop in Zhuhai to Guangzhou?" is classified as turning for help when Liz is living in host environment as foreigner. 
Additionally, Liz is working as English language teacher in Zhuhai, all her posts involving students, assignments, examinations and classroom are categorized into the type relevant to her job. When Liz is posting photos with family members like her husband, parents, and relatives or writing the texts as "Waiting for my parents to arrive! First time I get to see my father on Father's Day in 3 years!" "Camping with fam", the themes of posts are coded as family life. It is noted that Liz's travelling experience with her husband are frequently posted in WeChat Moments. Those posts are not coded as family life, but as her personal interest in travelling instead. Other posts concerning typical festival, food, ceremony, language (refer to Chinese character), art, places in China and America are correspondingly coded as characteristics in each culture. Finally, the posts with no clear designated meanings are put as others, with no shared theme.

\section{Results}

Over period of the year 2013-2015, total 135 posts shared by Liz via WeChat Moments are in descending order, the number decreased from 63 in 2013, to 44 in 2014 and 28 in 2015 (Table 1). The posts shared in 2013 are nearly the sum of posts in 2014 and 2015. Five main themes are identified in all posts as personal interests \& information needs; occupation; family; Chinese traits and American traits. The total number and percentage of posts in each category are shown in the following Table 1 . The posts about personal interests \& information needs (33.3\%) and occupation (20.4\%) occupy a half of all posts, while those on culture are up to $23.7 \%$.

Table 1. Number of Moments' Posts in 2013/2014/2015

\begin{tabular}{|l|c|c|c|c|}
\hline \multicolumn{1}{|c|}{ Years } & 2013 & 2014 & 2015 & Total (\%) \\
\hline $\begin{array}{l}\text { Personal interest \& } \\
\text { needs }\end{array}$ & 22 & 12 & 14 & $48(33.3 \%)$ \\
\hline Occupation & 14 & 9 & 7 & $30(20.4 \%)$ \\
\hline Family (life) & 10 & 10 & 3 & $23(15.6 \%)$ \\
\hline American traits & 9 & 4 & 2 & $16(10.8 \%)$ \\
\hline Chinese traits & 6 & 9 & 1 & $10(12.9 \%)$ \\
\hline Others & 63 (6 repeated) & 44 (3 repeated) & $28(2$ repeated) & \\
\hline Total & &
\end{tabular}

\subsection{Theme one: Personal interests and information seeking}

The posts relevant to personal hobbies reach to 39 , with only 9 posts are about seeking information. More specifically, the interests can be further divided into subgroups like traveling (36) and gardening (3 posts). Within the subgroup of traveling, 31 posts are photos of scenery and individuals, and 5 posts are about food (as shown in Figure 1). These posts vividly narrate Liz's rich traveling experiences in places like Cambodia, Hong Kong, Korea, India, Indonesia, Japan, Nepal, Thailand and places in China. Her photos and text 
definitely convey the message that she is keen on traveling thus traveling lover is appropriate to describe her unique personal quality.

From her posts, Liz is believed to be a person fond of taking risks. She not only enjoys sightseeing but likes adventure travel by hiking, camping and climbing mountains.
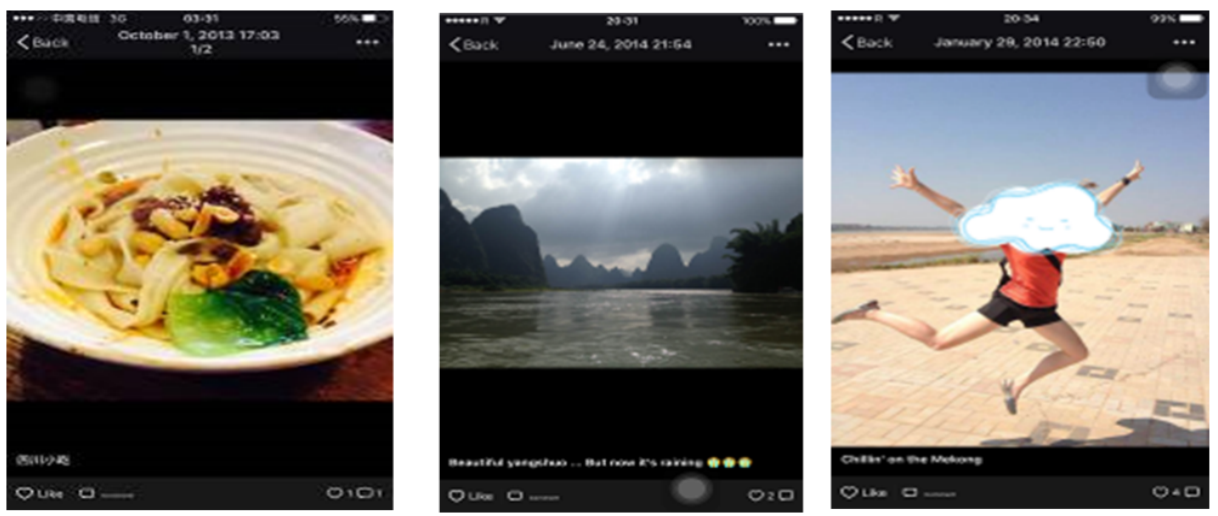

Fig. 1. Traveling: food \& Scener

This feature is particularly shown in the text of one screen shot, "Even the British Army turned back...too dangerous and impossible... deep snow and cold, but we did it". In terms of gardening, the theme focuses on Liz's preference to planting, enjoying self-planted food and fertilizer. Then Liz as a foreigner certainly needs helpful information when in the new environment. Therefore, she posts her needs in the Moments intending to get help from local people.

\subsection{Theme 2: Occupation}

Liz's posts (totally 30) apparently reflect her role as English speaking and writing teacher. These messages range from assignment, examination to in-class teaching (Figure 2). The first screen shot expresses Liz's hard work when grading students' journals.
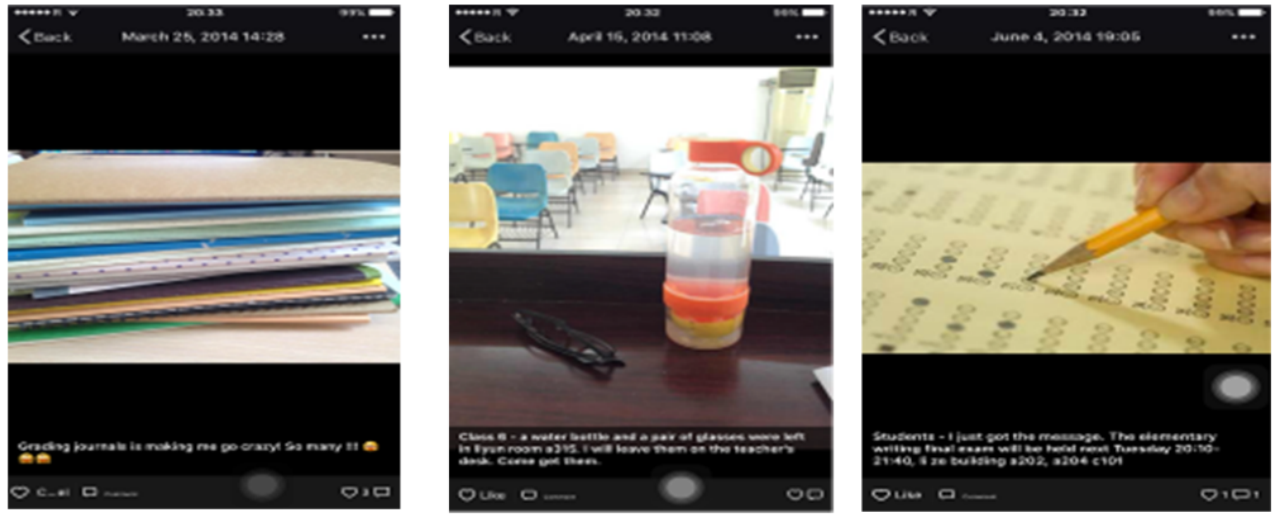

Fig. 2. The role of teacher

The second aims to remind students of their lost personal belongingness in the class and the third acts as the notice announcing the examination time. All the posts incorporate the role of students when Liz plays the role of teacher. Liz also shares her posts to assist 
students who forgot to write down their names on assignment paper and who are eager for overseas learning. In addition, she takes photos with students as memory when onesemester class is ended. In this sense, Liz is thought to be a caring and responsible teacher and her relationship with students is very nice.

\subsection{Theme three: Family}

23 out of 135 posts talk about Liz's family life. All the family posts convey Liz's personal information. She got married in 2010 and now is living in Zhuhai with her husband. She "tells" us via posts that she plays a role of daughter as well as wife in family. She gets the Easter gift from her mother and takes her parents traveling in Beijing when they came to visit her in 2014. On the other hand, her married status could be easily identified by taking photos together with her husband. But this is not the criterion to categorize the posts into the theme of married life. The posts which Liz uses the words as "husband", "hubby", her husband's name, or the personal photos symbolize the wedding and anniversary are counted. It can be inferred that her happy and satisfying family life in Zhuhai.

\subsection{Theme four: Chinese culture}

When Liz from America comes to work in Zhuhai, how does she respond to the new culture? Primarily, differences like food, language, and social practice are illustrated Figure 3. Hot pot, especially in Sichuan province, is of great popularity all over China. As shown in the first screen shot, the spicy hot pot, chopsticks and drinks “王老吉” (Wang Laoji, a Chinese herbal tea, and perfect match for hot pot) all reflect being a part of Chinese culture. In the second and third screen shots, Liz is interested in traditions of Chinese wedding. The Chinese character “喜” ( $X i$, indicating double happiness) is particularly used in wedding such as printed on invitation card, pasted on windows and doors, and embroidered in wedding dress. And the red umbrella opened up in the wedding ceremony implies auspiciousness, joyfulness and good luck.
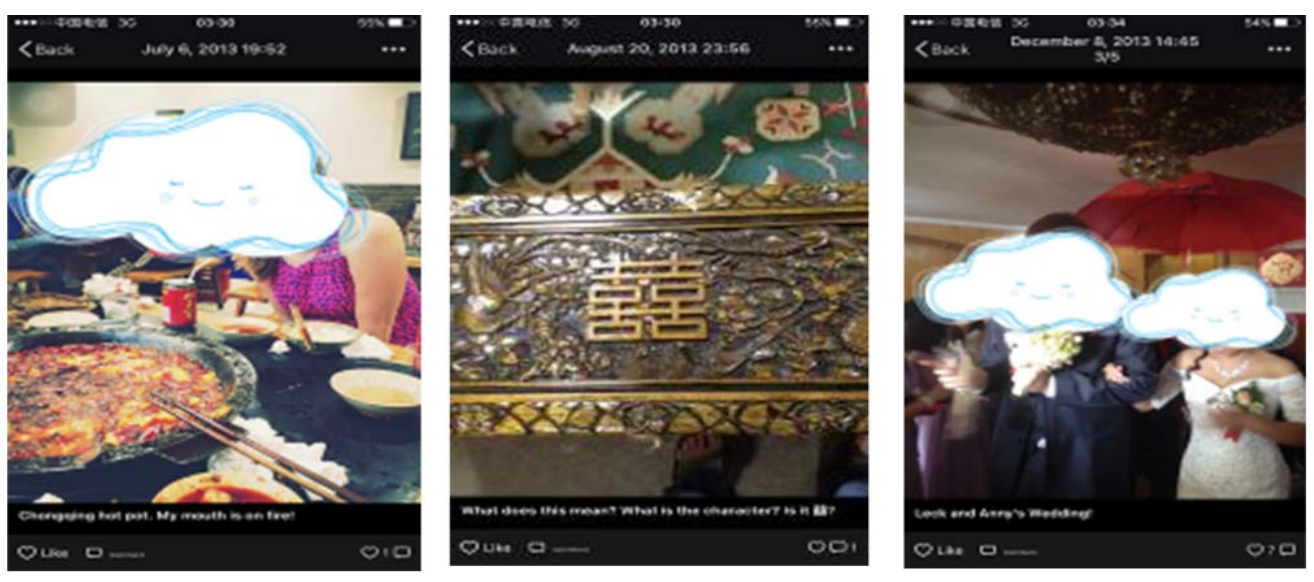

Fig. 3. Chinese traits (1)

Based on her experience of Chinese cultural, Liz makes a comparison between American and Chinese traits, and then attempts to use Chinese language. 
As an example in Figure 4 points out, the "American" coffee sold in China is only the instant coffee and costs too much than that in America. The other interesting case is food difference shown in "Last meal in America (chips, tomatoes \& beef)" and "First meal in China (Changfen, steamed rice rolls)". Though differences exist, Liz loves both of them based upon her use of emoji, smiling and loving faces. These comparisons of Chinese and American cultural traits, to some extent, indicate Liz's cultural sensitivity.

Apart from awareness of cultural differences, Liz also attempts to display Chinese culture and use Chinese character to express her ideas.
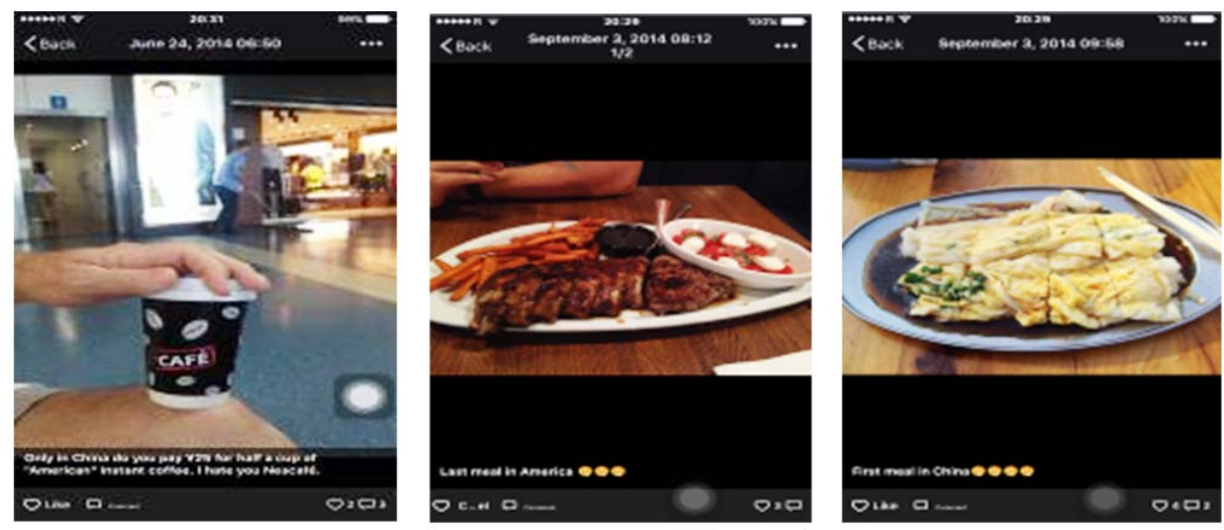

Fig.4. Chinese traits (2)

In one of the screenshots concerning Chinese culture, Chuanju (a type of Chinese opera originating in China's Sichuan province) is exhibited from the perspective of Liz. Correspondingly, Putuo temple (the largest temple of Buddhism in Zuhai) is also shown in another. Sitting the middle, Liz uses Chinese text “再見廣西” (Zai jian Guang xi, Farewell to Guangxi), expressing her enjoyment and her Chinese language learning.

Furthermore, Liz points out the error of information expressed in Chinese. For instance, in one screenshot, Chinese characters are written in the back-package of Heinz Ketchup, meaning that this product can be used in Chinese dish, pizza, bread and so on. But Liz makes her comment at the bottom of the text "Do not trust Heinz! Ketchup does NOT belong on spaghetti, enchiladas, pizza, or croissants." And in the other post, Liz further clarifies that "...Ketchup is a condiment for French fries, hot dogs, hamburgers, and sandwiches and .... It should not be used as a sauce to cover noodles. Some things don't belong together. Noodles and ketchup are two of those things..." In this case, Liz creatively uses her knowledge about American and Chinese food and recommends the correct way to do the cooking.

\subsection{Theme five: American traits}

When adapting to the Chinese culture, Liz's ethnic culture doesn't disappear when in host environment. She maintains the features rooted in American culture while experiencing Chinese culture. The themes about American traits could be identified by through Liz's "narration" of America as home. In the posts, she shared her hometown, graduated university, American holidays and foods. These messages, originated from being an American, transcend the geographical boundary, from locally to nationwide. Locally, Liz's hometown, Western North Carolina is posted as well as food in her hometown. Then it is the university where she studies. To a larger scale, as an America, she also posts photos 
about food and holidays celebrated in western country, like Easter, Thanksgiving and Christmas. In her family in Zhuhai, Liz often shares her homemade western food in WeChat Moments.

\section{DISCUSSION AND FINDINGS}

The five main themes have already been identified and described in Liz's 135 posts over last three years. Intercultural identity is defined by [6] as "an acquired identity constructed after the early children childhood enculturation process through the individual's communicative interactions with a new cultural environment". With regards to foreigners living and working in China, their identity shaped by the original culture and their identification to that group will be expanded beyond the conditioning of the original culture. Based up [7] and [16] explanation of intercultural personhood, the intercultural identity could be understood in the three dynamic phases of stress-adaptation-growth instead of and either/or state.

Among Liz's 135 posts, the number of posts concerning culture amounts to 35 (23.7\%). Her identity as Chinese culture experiencer is revealed by her descriptions of Chinese traditions, contrasts between American and Chinese cultures and usage of Chinese language. There clues indicate that Liz is conscious of cultural differences and gradually "transform" herself. This is supported by [18] as "A different cause for transformation in the voluntary integration of a new sign into an old system, not because a particular old sign is no longer available, but just because the new one becomes available". To step further, these posts as signs are described by Leeds-Hurwitz as assimilation, the relatively straightforward acquisition of a sign by one culture from another.

Generally, not much anxiety and stress during Liz's acculturation process are shown by her posts, which may because Zhuhai is not her first destination in China. Most cultural posts reflect Liz's active and ongoing adaption to Chinese culture. Some posts even indicate her creative use of cultural knowledge especially Chinese language knowledge to express herself. Therefore, her posts indeed show the influence of culture on acculturation and thus ascertain the likelihood to further explore the foreigners' identity in Chinese culture. Though the universalized identity is out of possibility to investigate in the present case study, an individualized identity defined by [6] is salient reflected by Liz's acceptance of Chinese culture and seeking of intimate personal relationship with people from host environment.

\section{REFERENCES}

1. Y. Y. Kim, ICS, 4, 1 (1994)

2. M. J. Collier, M. Thomas, Theor. ICC, 99, 122, (1988)

3. S.Ting-Toomey, In R. Wiseman \& J. Koester (Eds.), Intercultural communication competence, 72-111, (1993)

4. S.Ting-Toomey, In W. Gudykunst (Ed.), Theorizing about intercultural communication, 195-210, (2005)

5. T. Imahori, W. Cupach, In W. Gudykunst (Ed.), Theorizing about intercultural communication, 195-210, (2005)

6. Y. Y. Kim, Becoming intercultural: An integrative theory of communication and cross-cultural adaptation, (2001)

7. Y. Y. Kim, IJIR, 32, 359, (2008)

8. T. J. Milstein, IJIR, 29 (2), 217, (2005)

9. M. J.Pitts, Paper presented at the annual conference of ICA, (2007) 
10. R.Suro, Strangers among us: How Latino immigration is transforming America, (1998)

11. C. Rongwei, X. Yihan, Z. Yi, Chin. J.Sociol, 34(4), 25, (2014)

12. Z.Wenhong, L. Kaichun, Sociol.Stud, 4, 61 (2009)

13. W.Zhonghui, Z.Pan, G. Jin, Chin. J. Spec.Edu, 174, 86, (2014)

14. H. Jiong-mei, Y. Xue-ling, J. Xinjiang NU, 35 (2), 129, (2014)

15. S. Ye, Master dissertation, ECNU, (2010)

16. X. D.Dai, CMR, 5 (2), 1, (2009)

17. T. L. Sandel, B. Ju, In T. Milburn (Ed.). Communicating user experience: Applying local strategies to digital media design, 103-126, (2015)

18. W. Leeds-Hurwitz, Semiotics and communication: Signs, codes, cultures, (1993) 